\title{
Research on the Internal Control of Guarantee Company
}

\author{
Fu liuyang \\ Management School of WUhan University of Technology \\ Wuhan Hubei in China \\ 1813641408@qq.com
}

\begin{abstract}
Keywords:Guarantee Company ; Internal Control ;Recommendation Measures.
\end{abstract}
\begin{abstract}
Guarantee companies, as emerging non-bank financial entities under the international economic development, are recognized as a high-risk industry. As a platform for financing guarantee company, Guarantee companies connect firms and banks.It has a far-reaching impact on social and economic development, as well as small and medium enterprises financing. Internal control is important that is to regulate the internal management, to reduce credit risk, to alleviate the problem of financing, to optimize the allocation of resources, to improve economic efficiency.The internal control research of Guarantee companies, which can analyze problems and make a number of recommendations on the rationalization of internal control issues.
\end{abstract}

\section{Introduction}

China's investment guarantee companies, as an emerging institutional strength, the industry team is constantly growing and expanding. Although the development of the guarantee company has made some achievements, but at the same time, Beijing "in the event", "Hebei financial investment guarantee" and other events, Which is also a serious impact on the guarantee companies and the whole industry. Therefore, it is necessary to strengthen the research on the internal control of the guarantee company and establish and perfect the construction and implementation system of its internal control.

\section{Overview of the Guarantee Company}

2.1 Definition and Elements of Internal Control. On May 22, 2008,china defined internal control as: the enterprise board of directors, board of supervisors, managers and all other employees to implement, for the realization of corporate control objectives of the entire process. ${ }^{[i]}$ The internal control elements in the Basic Standard for Enterprise Internal Control should include five elements: internal environment, risk assessment, control activities, information and communication, and internal supervision.

2.2 The Meaning and Operation Mode of Guarantee Company. The term "guarantee company" refers to a limited liability company and a joint stock limited company established according to law , and operates a credit guarantee business.

At present, the mode of operation of the security company formed a "one body two wings" pattern: one is the central government-based policy-based security model, the wings is a commercial guarantee and mutual guarantee model. 
Table 1: The Status Quo of Cthe comparison chart three guarantees

\begin{tabular}{c|c|c|c|c}
\hline Guarantee model & The proportion & Sources of funds & Guarantee object & Guarantee Features \\
\hline $\begin{array}{c}\text { Policy- } \\
\text { based guarantee } \\
\text { company }\end{array}$ & $90 \%$ & $\begin{array}{c}\text { Government budget } \\
\text { allocation and so on }\end{array}$ & $\begin{array}{c}\text { The state's key } \\
\text { support industries }\end{array}$ & $\begin{array}{c}\text { Policy- } \\
\text { oriented and } \\
\text { standardized } \\
\text { market- } \\
\text { oriented operation }\end{array}$ \\
\hline $\begin{array}{c}\text { Commercial } \\
\text { guarantee company }\end{array}$ & $5 \%$ & $\begin{array}{c}\text { Private investment- } \\
\text { based }\end{array}$ & $\begin{array}{c}\text { A certain size and a } \\
\text { certain profitability } \\
\text { of SMEs }\end{array}$ & $\begin{array}{c}\text { Independent legal } \\
\text { and commercial } \\
\text { operation }\end{array}$ \\
\hline $\begin{array}{c}\text { Mutual Guarantee } \\
\text { Company }\end{array}$ & $5 \%$ & $\begin{array}{c}\text { Membership shares } \\
\text { and so on }\end{array}$ & $\begin{array}{c}\text { Member companies } \\
\text { self-financing, at } \\
\text { their own risk }\end{array}$ \\
\hline
\end{tabular}

\section{China Guaranty Company and the Problems of Internal Control.}

3.1 The Status Quo of China Guaranty Company. As can be seen from the table 2 , although the impact of the national macro-control policies, security companies in recent years, the development trend has declined, but the entire security industry is still maintaining steady growth momentum. In the decade 2001-2011, the pace of development in 2004 in the first ten years, the growth rate reached $126.5 \%$. As of the end of 2011, China has more than 8402 security companies.

Table 2: 2001-2011 China's number of security companies chart

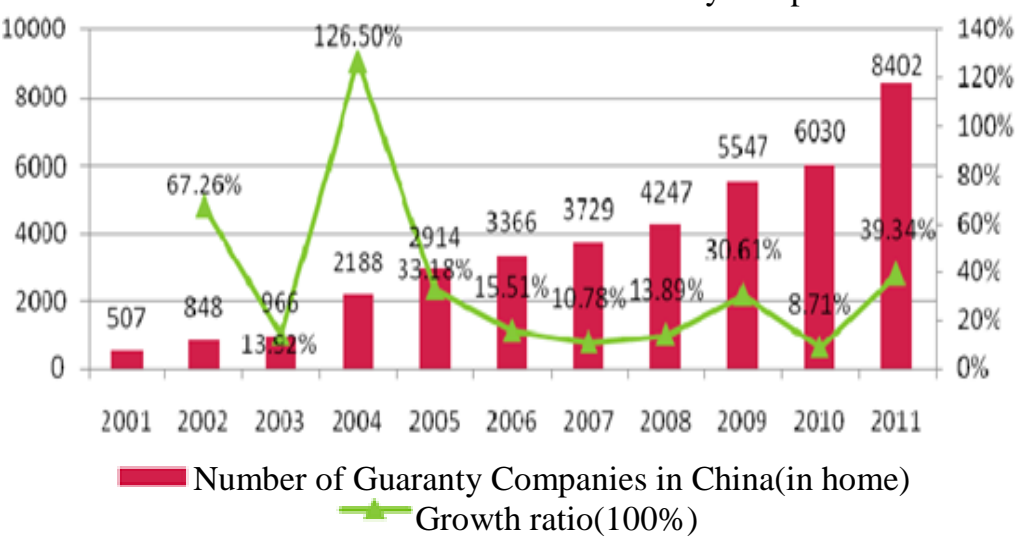

3.2 Problems in Internal Control of China Guarantee Company. According to the five elements of internal control analysis, the internal control of the guarantee company mainly lies in the risk management aspect. ${ }^{[2]}$

\subsubsection{Weak risk assessment awareness}

The risks of the Guarantee company are mainly "guarantee risk", "credit risk", "default risk", "moral hazard" and "financial risk". The high concentration of risk and the difficulty of defusing directly affect the operation effect and enthusiasm of the guarantee company. But the practice of Chinese security companies risk assessment awareness is weak and lack effective risk assessment.

\subsubsection{Weak risk compensation mechanism}

Most of Chinese guarantee institutions are still at an early stage of development. At this stage, the risk compensation mechanism of the guarantee institution is very important. But in China, although the government strongly supports the development of the guarantee industry, there is still a lack of similar risk compensation mechanism.

\section{Risk Analysis of China Guarantee Company}

China's credit guarantee companies operate credit guarantee business, because of various asymmetric, non-smooth phenomenon, its own business operations in the process by the subjective 
and objective, internal and external factors, resulting in a different risk, the security industry has therefore been recognized as high-risk industry one.

\subsection{External risk}

\subsubsection{The government risks}

Government departments to the risks of financing guarantee agencies mainly for SMS policy instability and government departments to guarantee industry is inappropriate intervention in two ways.

\subsubsection{The risks to Banks from cooperation}

The current industry is a prominent problem, the bank and the security company's cooperation is not equal, there is no risk-sharing mechanism. Once the borrower defaults, the guarantee company needs to bear all the losses. In layman's terms, a good customer bank to keep their own, less qualified customers to the security company - this is a kind of unequal relations of cooperation.

\subsubsection{Risk of default of guaranteed enterprise}

The default risk of the guaranteed enterprise refers to the risk that the guaranteed company can not repay the loan in time and in full amount, and the risk of the guarantee company is not only related to the existing problems of the guaranteed enterprise, but also may be related to the single guaranteed business situation.

\subsection{Internal risk}

Guarantees the company's own risk incentives mainly from the following aspects: (1) guarantee the quality of personnel is low. The lack of necessary professional conduct, business processes are not easily carried out in accordance with the provisions of induced operational risk;(2) the internal control system is imperfect, management is unscientific. The division of responsibilities is not clear, the examination and approval system is not detailed, the construction of internal control system does not attach importance to the security agencies is a common problem; (3)The security company employees for their own interests and the applicant business collusion, the security company placed in high-risk environment.

\subsection{The Necessity of Strengthening Risk Control of Guarantee Business}

Guarantee business is a high-risk economic activities, the frequent outbreak of the guarantee lawsuit so that many companies suffered heavy losses. Many companies guarantee each other to form a "guarantee circle" into the vortex of security; and some companies to provide security guarantees, or even false security.

\subsubsection{Frequent non-compliance guarantee}

Violation of guarantees increases the burden of listed companies and difficulties, and even downs the business. Shanxi Dahlman's decline, digital mapping of the delisting, the collapse of Xinjiang Deron, etc, are related to non-compliance guarantee.

\subsubsection{Enterprises by the mutual guarantee}

Many companies each other to provide security for each other in the formation of chain sets of mutual insurance. The link relationship between the main chain of security is not transparent, easy to prevent and control, it is difficult to take appropriate preventive measures. Chain guarantee has a sudden, when there is a problem with the debt chain, the guarantor is often in the position of the person being executed, directly face property damage.

\section{Suggestions on Establishing and Perfecting Internal Control of Guarantee Company}

5.1 Strengthen the control environment, establish and improve the internal control framework. Control of the environment is good or bad, which direct impact on the internal control of security companies to follow and implementation, as well as the company's business objectives and overall strategic objectives. We should pay attention to improving corporate governance structure, pay attention to human resources management, strengthen the analysis of posts and the risk management culture, improve the quality of management.

5.2 Develop internal control index and strengthen risk assessment. The purpose of internal control construction is not to eliminate risk, nor to reduce risk, but to control it within the scope of risk. So we must first establish a scientific and reasonable standards, the development of internal 
control index to measure of the level of risk management of security companies comprehensively.

5.3 The establishment of dynamic control activities. The establishment of dynamic control activities requires enterprises to adhere to the appropriate division of responsibilities and separation, strict authorization control, improve the accounting system control, attention to property protection and control, the implementation of a comprehensive budget control, the establishment of operational analysis and control. ${ }^{[3]}$

5.4 Strengthen information flow and communication. A sound internal control system is inseparable from a complete set of information transmission, communication and feedback information system. Today's society is the information society, Guarantee the effective operation of internal control requires companies to establish information flow and communication system, a clear relevant information collection, processing and transmission to ensure the flow of information and communication.

\section{References}

[1] England \& Wales : ICAEW ,Internal Control : Revised Guidance for Directors on the Combined Code ,Finacial Reporting Council ,vol. 10,2005.

[2]Li ziyu ,A Case Study of Internal Control of Investment Guarantee Company ,Beijing Jiaotong University, 2015.

[3]Yan yehua and Zhenjun ,Reflections on Construction of Internal Control of Guaranty Company ,Encyclopedia ,vol. 01, pp. 185-186, 2011. 